\title{
A new kind of superconducting machine
}

\author{
Rada Alhasan, Thierry Lubin, Zheksenbek Makeyevich Adilov, Jean Lévêque
}

\begin{abstract}
The aim of this paper is to present a new concept of superconducting inductor for a synchronous machine. This inductor consists of two superconducting coils. These coils have the same axis and are fed by the same current. A superconducting bulk is placed between the two coils in order to obtain a variation of the flux density in the air-gap. This bulk is surrounded by a ferromagnetic material to improve the distribution of the air-gap magnetic field. With the proposed superconducting inductor, we obtain an electrical machine which presents two poles with a high value of the magnetic field in the air gap. In order to show the feasibility of this new superconducting inductor, a prototype has been built and experimental results are given in this paper.
\end{abstract}

Index Terms - Electrical engineering, Superconducting motors, Superconducting coils, Electromagnetic shield.

\section{INTRODUCTION}

$\mathrm{T}$ HE improvement of the electrical machines performance is a great challenge for several decades. One of the most important parameters to improve the performance of electrical machines is the generation of a high magnetic field in the air gap. Superconducting materials are very interesting due to their characteristics and their abilities to suppress the Joule losses and to allow very high current densities. It is now possible to design and to test superconducting motors and generators with high magnetic fields, in order to enhance the performance of electrical machines. Thus, it is possible to build lighter and more efficient electrical machines than the conventional ones. Another interesting property of bulk superconductors is their ability to shield the magnetic field. Initially, a superconductor is cooled under a zero magnetic field. Then, if a variation of magnetic flux occurs, the superconductor bulk expels the magnetic flux and acts as an effective magnetic shield. This behavior can be used to guide the flux because the magnetic flux into the superconducting stays equal to zero [1] as shown in Fig.1. It has been shown that this characteristic can be used to achieve efficient electrical machines [2-6].

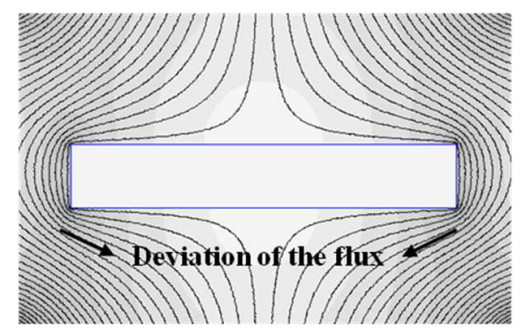

Fig. 1. Shielding effect obtained with a superconducting bulk.

Rada Alhasan is with the Groupe de Recherche en Electrotechnique et Electronique de Nancy, Université de Lorraine (GREEN), Nancy-FRANCE.

Thierry Lubin is with the Groupe de Recherche en Electrotechnique et Electronique de Nancy, Université de Lorraine (GREEN), Nancy-FRANCE.

Jean Leveque is with the Groupe de Recherche en Electrotechnique et Electronique de Nancy, Université de Lorraine (GREEN), Nancy-FRANCE.
In this paper, we propose an original concept of a superconducting inductor. This concept is attempting to significantly increase the air gap magnetic field. As shown in Fig. 2, this new inductor presents an original topology with two superconducting field coils and a superconducting magnetic shield. The superconducting coils can produce a high magnetic field. These coils are really easy to manufacture because they have a solenoid form. A superconducting bulk is placed between the coils and plays the role of a magnetic shield. This magnetic shield provides a variable magnetic field in the airgap (two poles). The result is an increase of the flux density in the air gap. The main objective of this paper is not to optimize the structure but to prove the feasibility of this new concept. From this inductor, we have designed, built and tested a generator that we also introduce in this paper.

\section{STRUCTURE OF THE MOTOR}

The studied electrical motor consists of a classical stator yoke and the original superconducting inductor that we propose in this paper. We will describe successively the inductor and the armature part of this motor.

\section{A. Inductor}

The structure of the proposed inductor is shown in Fig. 2. It consists of two coaxial superconducting coils. The coils are fed by direct currents having the same direction which generate the magnetic field (B1, B2) as shown in Fig. 2. An inclined superconducting plate is placed between the two coils. This superconductor bulk, which is located between the two solenoids, is used as a magnetic shield. So, beyond this superconducting bulk the magnetic field is null. Therefore, we obtain a spatial variation of the magnetic field in the air-gap.

In order to improve the radial flux density waveform in the air-gap, a ferromagnetic material (XC35 Carbon steel), is placed between the two coils on each side of the superconducting bulk. This ferromagnetic material will increase the radial component of the flux density in the air-gap. The inductor structure is similar to a claw-pole machine [7]. The increase of the magnetic field in the air gap, compared to conventional structures, should provide a high torque density. In our study, many 3D numerical simulations have been carried out to obtain the no-load air-gap flux density distribution. Figure 3 shows the distribution of the radial component of the flux density in the plane $(\theta, \mathrm{z})$ of the inductor (between the two

Zheksenbek Makeyevich Adilov is with Kazakh National Technical University, KazNTU, Named after K.I. Satybayev, 22 Satybayev, 050013 Almaty, KAZAKSTHAN. 
coils) at a radius that corresponds to the stator bore. This figure clearly shows that we obtain a two poles machine.

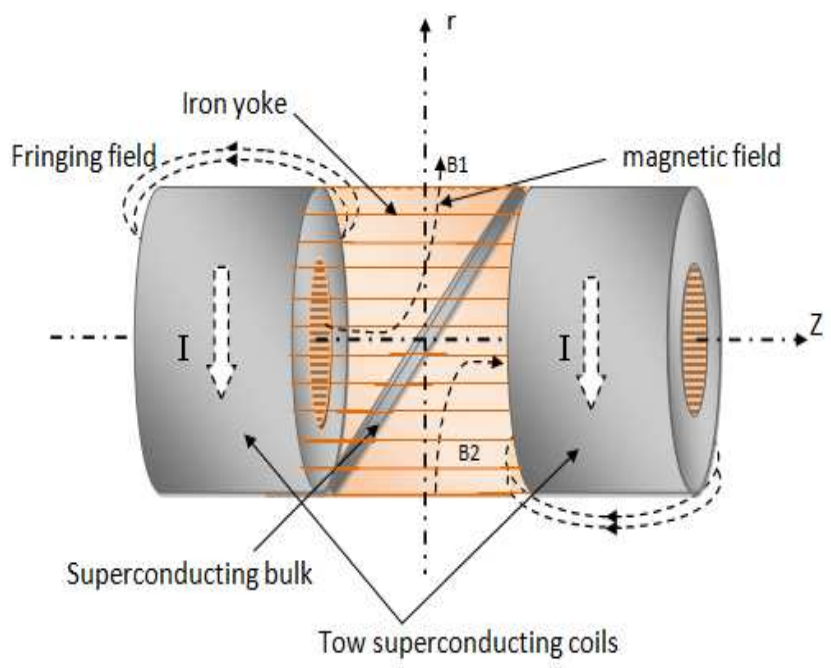

Fig. 2. Description of the superconducting inductor.

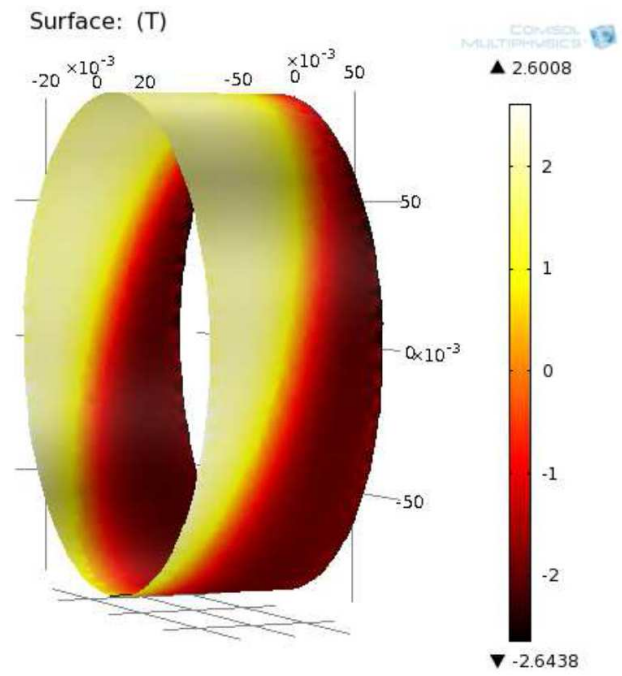

Fig. 3. Radial flux density distribution in the air gap.

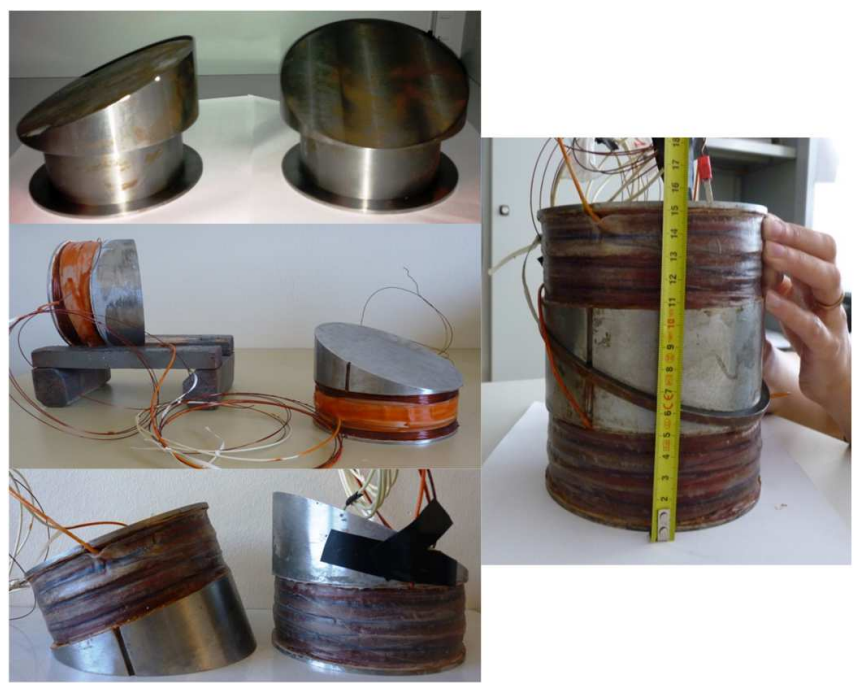

Fig. 4. Manufacture of the superconducting inductor.
In table I, we give some data about this superconducting inductor. Thanks to the superconducting inductor, we obtain a large value for the flux density (around 2.5T). Therefore we can expect a large value for the electromotive force and for the torque density. The different production stages for this inductor are shown in Fig. 4. We can see the two ferromagnetic parts, the superconducting coils, and the superconducting plate.

TABLE I

GENERAL PARAMETERS OF THE SUPERCONDUCTING INDUCTOR

\begin{tabular}{lll}
\hline \hline \multicolumn{1}{c}{ Parameters } & \multicolumn{1}{c}{ Unit } & Value \\
\hline Superconducting plate (material) & & YBCO \\
Thickness of the superconducting plate & $\mathrm{mm}$ & 10 \\
Diameter of the superconducting plate & $\mathrm{mm}$ & 150 \\
Superconducting coils (material) & & $\mathrm{NbTi}$ \\
External radius of superconducting coils & $\mathrm{mm}$ & 68 \\
Length of superconducting coils & $\mathrm{mm}$ & 45 \\
Length of the superconducting wires & $\mathrm{m}$ & 650 \\
Length of active part of the inductor & $\mathrm{mm}$ & 45 \\
Current density in superconducting coils & $\mathrm{A} / \mathrm{mm}^{2}$ & 700 \\
Length of the inductor & $\mathrm{mm}$ & 135 \\
\hline
\end{tabular}

\section{B. Armature}

The stator is a classical one, made with copper coils. This armature presents 48 slots. We used a three-phase single layer winding with diametrical pitch. The number of slots per pole and per phase is equal to 8, which is sufficiently large to filter most field harmonics due to the slots. A general view of the inductor with the armature is given in Fig. 5. In table II, we give some data about the three-phase armature.

TABLE II

GENERAL PARAMETERS OF THE THREE-PHASE ARMATURE

\begin{tabular}{|c|c|c|}
\hline Parameters & Unit & Value \\
\hline Number of slot & & 48 \\
\hline Internal radius & $\mathrm{mm}$ & 178 \\
\hline External radius & $\mathrm{mm}$ & 280 \\
\hline Length & $\mathrm{mm}$ & 45 \\
\hline Current density & $\mathrm{A} / \mathrm{mm}^{2}$ & 6 \\
\hline
\end{tabular}

Figure 6 represents schematically the path of a field line for this type of machine by considering the housing for the return path. This flux line path is not classical and is very different from that encountered in conventional machines. An important difference is that the return flux path is through the motor housing. It is worth noting that an important axial force exists on the two parts of the inductor. This must be taken into account for the design of the bearings.

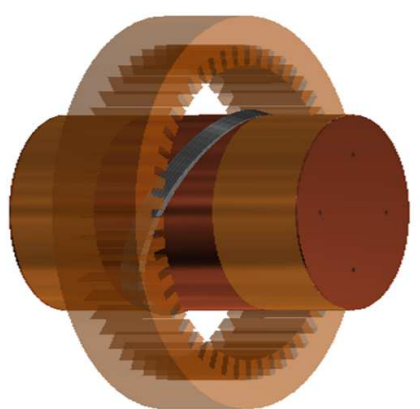

Fig. 5. Representation of the machine with its armature and its inductor. 


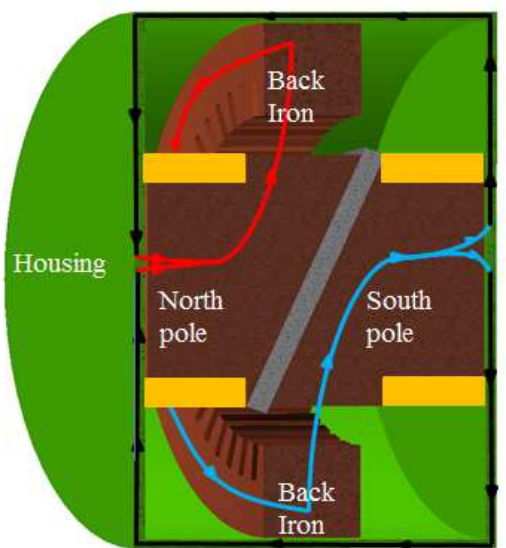

Fig. 6. Flux line path in the proposed motor with the back iron.

\section{EXPERIMENTAL RESULTS}

\section{A. Experimental Bench}

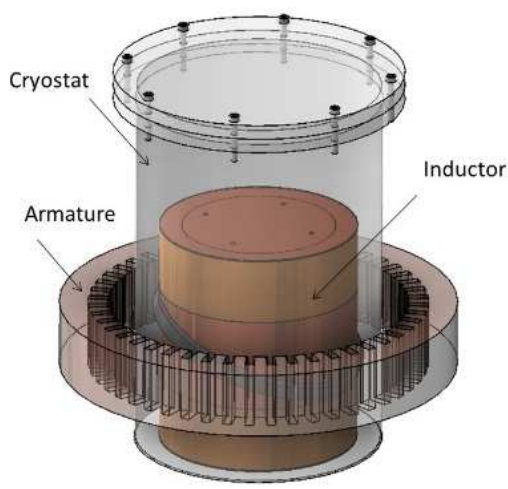

Fig. 7. Studied superconducting motor with its cryostat.

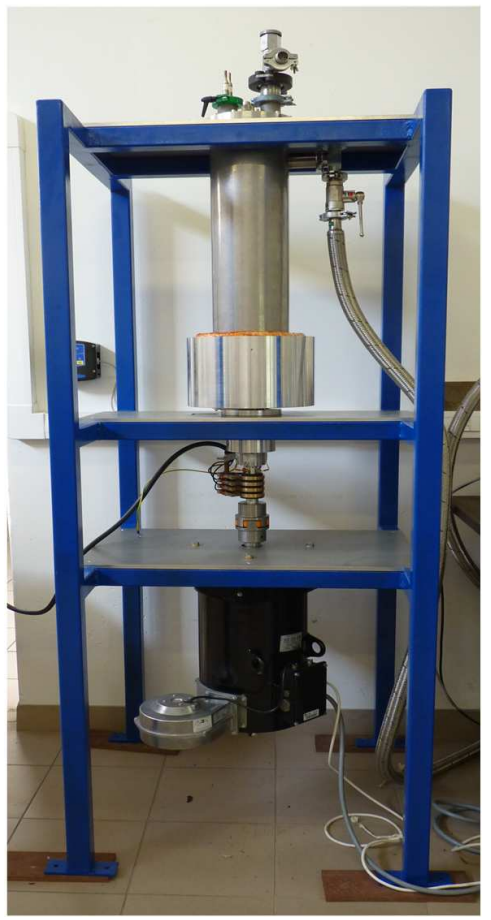

Fig. 8. Picture of experimental bench.
To simplify the topology and more exactly the cooling system, we chose to have a rotating armature driven by a DC motor. The superconducting inductor is locked and immersed in a bath of liquid helium. The overall pattern of the superconducting motor is shown in Fig. 7. The armature of the machine surrounding the cryostat acts as a rotor. It is carried by a movable aluminum support which is bound to the DC motor with a mechanical coupling. We use slip rings to feed the armature (one ring for the neutral and three rings for the phases). The whole system is shown in Fig. 8. Some important data about the motor are summarized in table III. The air-gap mentioned in table III is the magnetic air-gap between the inductor and the armature. The mechanical air gap between the outer diameter of the cryostat and the armature is equal to $1 \mathrm{~mm}$. TABLE III

GENERAL PARAMETERS OF THE SUPERCONDUCTING MOTOR

\begin{tabular}{llll}
\hline \hline \multicolumn{1}{c}{ Parameters } & Unit & Value \\
\hline Pole pairs & & 2 \\
Nominal speed & $\mathrm{rpm}$ & 500 \\
Motor air gap & $\mathrm{mm}$ & 18 \\
Operating temperature & $\mathrm{K}$ & 4.2 \\
\hline
\end{tabular}

\section{B. Experimental results}

Two types of tests were conducted:

- Preliminary tests: these tests allowed us to gradually put into operation the prototype. We initially checked the proper operation of superconducting coils and plate. We have also measured the back EMF.

- Tests of the machine as a generator (open circuit and short circuit tests): these tests allowed us to determine the parameters of the Behn-Eschenburg model. We finished the measurement campaign by a test under load condition, which allows us to validate the principle of electromechanical energy conversion.

Figure 9 shows the back EMF measurement for the three phases. We also give the harmonic analysis for one phase voltage in Fig .10. We can note that we obtain a sinusoidal magnetic flux distribution with this inductor structure. The space harmonics are greatly attenuated due to the large size of the gap which participates in the harmonic filtering (air gap of $18 \mathrm{~mm}$ due to the cooling system).

Figure 11 shows a comparison between the numerical and experimental values of the RMS value for the back EMF versus the field current for a speed of $500 \mathrm{rpm}$. We can note that the simulation and experimental results are identical and linear up to a value of the field current equal to $40 \mathrm{~A}$. Above this value, we can observe a significant difference between the two curves.

This can be explained by the fact that we don't take into account that there is a significant part of the magnetic field which arrives on the armature lamination along the $\mathrm{z}$-axis. Indeed, we have taken the same B-H curve in all the direction for the armature in the $3 \mathrm{D}$ numerical simulation. But this 
armature is made of ferromagnetic thin insulated iron sheets. Therefore, it is necessary to take into account a different B-H curve for the z-axis. This is under study.

In figure 12, we present the short-circuit test results. The speed is fixed to $500 \mathrm{rpm}$. The terminals of the machine are short circuited. The armature current has been limited to 2.1 $\mathrm{A}_{\text {rms }}$ that corresponds to a current density slightly greater than $5 \mathrm{~A} / \mathrm{mm}^{2}$ in the copper to avoid overheating. As in a conventional synchronous motor, this characteristic is linear. The synchronous reactance value for the studied motor is shown in Fig. 13. This reactance is obtained from the no-load test and the short-circuit test as usually done for a synchronous machine. This reactance is highly non-linear and decreases rapidly due to the heavy magnetic saturation of the ferromagnetic parts for this machine.

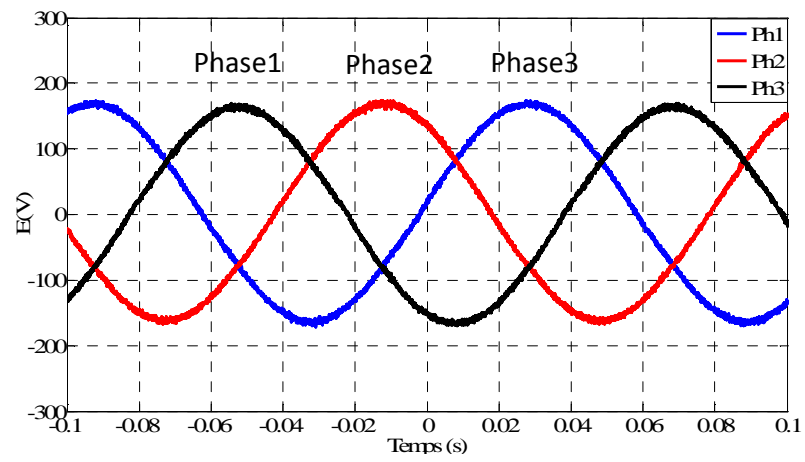

Fig. 9. Back EMF variation for a speed of $500 \mathrm{rpm}$.

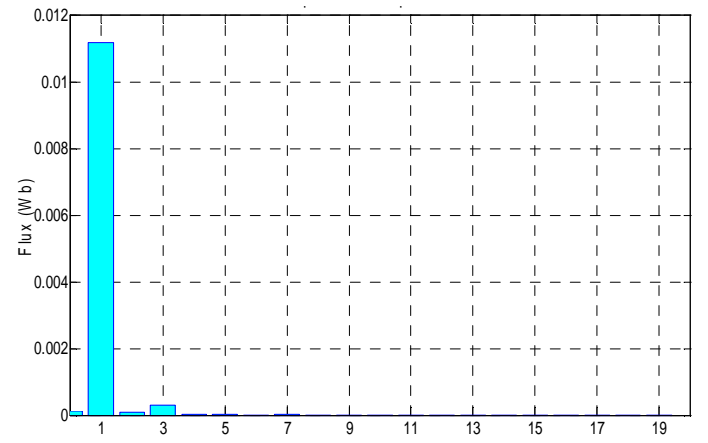

Fig. 10. Harmonic analysis of the back EMF for one phase.

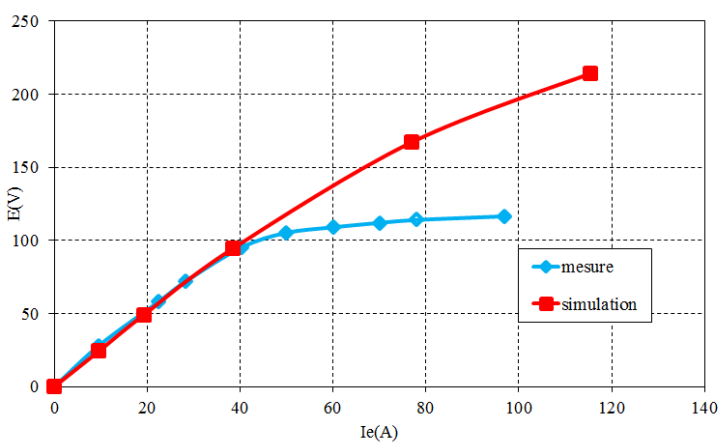

Fig. 11. RMS value of the back EMF versus the inductor current.

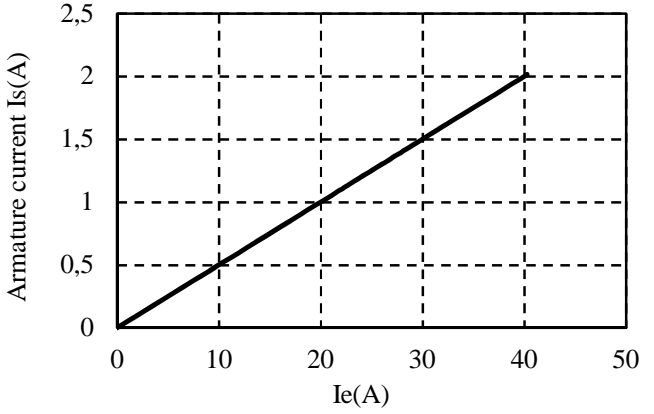

Fig. 12. Armature current versus inductor current for the short circuit test.

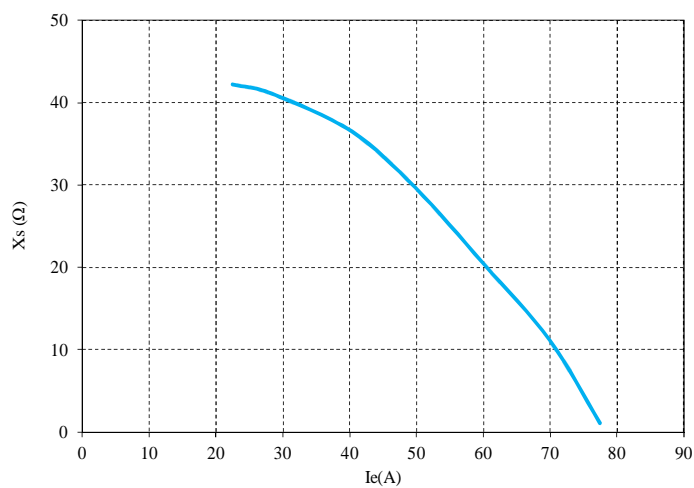

Fig. 13. Synchronous reactance versus the inductor current.

\section{CONCLUSION}

We have designed and built a scale prototype of a superconducting machine with a new inductor topology. We have, through various tests under no-load and load conditions, validated the principle of the electro-mechanical conversion of the proposed topology. Moreover, we have also validated the numerical model used for the design even if this model is not the subject of this paper. The results show the technical feasibility of this machine. The no-load and the short circuit test allowed us to determine the parameters of the Ben-Eschenburg model for this machine.

\section{REFERENCES}

[1] T. Kiyoshi, S. Choi, S. Matsumoto, T. Asano, et D. Uglietti, Magnetic flux concentrator using $\mathrm{Gd}-\mathrm{Ba}-\mathrm{Cu}-\mathrm{O}$ bulk superconductors. IEEE Trans. Appl. Supercond, Vol. 19, No. 3 (June 2009), pp. 2174-2177.

[2] E. Ailam, D.Netter, J.Lévêque, B.Douine, Philippe J. Masson, Member, IEEE, and A.Rezzoug, Member, IEEE, Design and testing of a superconducting rotating machine, IEEE Trans. Appl. Supercon., Vol. 17, No. 1, March 2007.

[3] R.Moulin, J.Lévêque, L.Durantay, B.Douine, D.Netter, and A.Rezzoug, Member, IEEE, Superconducting multistack inductor for synchronous motors using the diamagnetism property of bulk material, IEEE transactions on industrial electronics, Vol. 57, No. 1, January 2010.

[4] P. Tixador Superconducting electrical motors. International Journal of Refrigeration, CNRS-CRTBT/LEG, B.P. 166, 38042 Grenoble Cedex 09, France, 22 (1999) 150-157,

[5] D. Netter, J. Leveque, E. Ailam, B. Douine, A. Rezzoug, and Philippe J. Masson, Theoretical study of a new kind HTS motor, IEEE Trans. Appl. Supercon., Vol. 15, No. 2, (June 2005).

[6] P. Masson, J. Leveque, D. Netter, and A. Rezzoug, Experimental study of a new kind of superconducting inductor. IEEE Trans. Appl. Superconductor., Vol. 13, No. 2, Jun. 2003, pp. 2239-2242.

[7] G. Barakat, A. Foggia, M. Ivanes, R. Periot, A. Masson, Three dimensional computation of claw-pole synchronous machine performances. in Proc. Int. Conf. Elect. Mach. (ICEM), Vol.3(1994), pp.116-121. 